\title{
3M syndrome
}

INSERM

\section{Source}

INSERM. (1999). Orphanet: an online rare disease and orphan drug data base. 3 M syndrome. ORPHA:2616

3M syndrome is a primordial growth disorder characterized by low birth weight, reduced birth length, severe postnatal growth restriction, a spectrum of minor anomalies (including facial dysmorphism) and normal intelligence. 